nosis should be included. The second ranked formulation, the fifth, and to a lesser extent, the fourth, were strongly criticized for inadequate attention to management and prognosis. This criticism did not seem to mark down these formulations to any great extent.

The concept of formulation that finds agreement among examiners is different from the so-called 'psychodynamic formulation', which may be more appropriate in a psychotherapeutic setting. This study cannot throw any light on such a formulation, but the description by Aveline (1980) is worth noting.

\section{BIBLIOGRAPHY}

Aveline, M. (1980) Making a psychodynamic formulation Bulletin. The Royal College of Psychiatrists, December, 192-3.

Ben-ARon, M. \& McCormick, W. O. (1980) The teaching of formulation. Canadian Journal of Psychiatry, 25, 163-65.

Greenberg, M., Szmukler, G. \& Tantam, D. (1982) Guidelines on formulation. Bulletin of the Royal College of Psychiatrists, 6, 160-62.

Kendell, R. E., Affleck, J. \& Zealle, A. (1978) Diagnosis and classification. In Companion to Psychiatric Studies (eds. A. Forrest et al). London: Churchill Livingstone.

Menninger, K. (1963). The Vital Balance: The Life Process in Mental Health and Illness. New York: Viking Press.

Royal australian and New Zealand College of PsychIATRISTS (1980) Examination Booklet of Information for Candidates, p. 8.

Royal College of Psychintrusts (1979) Scribe's Column Diagnostic formulation. Bulletin of the Royal College of Psychiatrists, June, pp. 108-9.

SIRGEL, S. (1956) Non-Parametric Statistics for the Behavioural Sciences. New York: McGraw-Hill.

Formulation

APPENDIX

A 34-year-old married mother presented with increasing selfdenigration and doubt over her mothering since the birth of her second son, three months previously. Over this time she had become indecisive and unable to assess her behaviour appropriately. She ruminated obsessively, doubting that she was a good mother and feeling that her children would suffer because of this in the future. She felt very guilty, had contemplated suicide and infanticide. There was a one and a half month history of anorexia, loss of weight, early morning waking, guilty ruminations, diurnal mood variation, spontaneous weeping, decrease in libido, and constipation.

There were no other somatic symptoms nor any other significant psychological stress or physical ilinesses.

There was no family history of treated psychiatric illness, although both her parents suffered from mild stress-related depression.

She never felt close to her parents or siblings and had always felt shy. She had always had a small circle of friends and did not describe any significant difficulties with adolescent heterosexual relationships. Academically she had done well and trained as an anaesthetic sister.

She had no past history of psychiatric treatment nor any evidence of a cyclothymic personality. She exhibits an obsessional personality-characterized by perfectionism in her work, conscientiousness and rigidity of thinking, and a need to keep proving herself by continually setting unattainable goals.

Mental state examination showed an intelligent woman with no evidence of schizophrenia or organic deficit. She had only mild depressive affect, but was agitated. Her thoughts were marked by obsessional circumstantiality and overvalued ideas centering on doubts and guilt about her ability as a mother. Her most obvious defence mechanisms were denial and rationalization.

Physical examination was normal.

The provisional diagnosis is a severe post-partum depressive illness in a woman with an obsessional personality.

I did not feel that there was any other diagnosis applicable at the time. As this was her first severe depressive illness, there is no past history of cyclothymic mood swings, and her family history indicates depressive reactions, 1 would provisionally call this a unipolar affective illness.

Management plans

1. Admit with her baby. Observe closely on non-specific management for several days.

2. Further assessment of the patient, and her relationship to her son. 3. History from husband.

\title{
Public Lectures Organized by the British Psychoanalytical Society
}

1982 marked the 50th anniversary of the Public Lectures Committee of the British Psychoanalytical Society. Over this period various events have been held to introduce psychoanalytic concepts to a wider audience in related professions and disciplines. For example, many will remember the Winter Lectures that were held in the 1960 s.

More recently, the trend has been to hold one-day events in London aimed at a wider audience. Recent topics have been: basic psychoanalytic concepts; psychoanalysis and women; the mind of the criminal; problems in the class room; self-destructive acts; and child abuse. In the last year the day-course on basic psychoanalytical concepts has also been held in Leicester, Birmingham and Belfast, by the invitation of the local professor of psychiatry in each centre. The aim has been to stimulate interest in any local teaching programmes, and to mitigate the centralization of psychoanalytic resources in London.

If any Department of Psychiatry outside London would be interested in such a day event, they should get in touch with the Public Lectures Committee at the Institute of Psychoanalysis, 63 New Cavendish Street, London W1.

Jonathan Pedder 